Capuzzo, Guy. 1. 2009 “Sectional Tonality and Sectional Centricity in Rock Music.” Music Theory Spectrum 31.1, pp.157-174.

Made Available courtesy of the University of California Press: http://www.ucpress.edu/

Sectional Tonality and Sectional Centricity in Rock Music

\section{GUY CAPUZZO}

Keywords: Tonality, Sectional Tonality, Centricity, Sectional Centricity, Rock Music, Radiohead, Karma Police, King's X, Julia

\section{SECTIONAL TONALITY}

Describing a subset of the rock repertory, Walter Everett writes:

Some songs alternate between unrelated key areas, each expanded in entire sections, creating a nontonal whole . . . [Other] songs are structurally diatonic and depend on normal tonal chord progressions, and yet no single overriding tonal center can be appointed conclusively because the song's various formal sections revolve around separate tonics ... and closure is not provided by any overall directed voice leading (Everett 2008, 144-45; emphasis added).

I have italicized the words "unrelated" and "nontonal" to raise two issues. First, Everett does not mean "unrelated" in the sense of a pair of keys being related. Pairs of keys in these songs are often related-even closely related. Second, as is evident from the last sentence of the quote, Everett's gauge of tonality is Schenkerian. Scholars including Everett routinely apply other gauges of tonality to the analysis of rock music, such as directional or progressive tonality, so it is reasonable to ask if the songs Everett refers to might be deemed tonal by some other measure (Everett 2004, §14-15; Harrison 2004; Ricci 2000). However, directional

I wish to thank Mark Anson-Cartwright, Christopher Doll, Shaugn O'Donnell, and the anonymous readers for feedback on this paper. tonality accommodates two keys at most and only models songs that start and end in different keys, while the songs Everett describes often feature three or more keys. Further, the two key songs sometimes start and end in the same key. While scholars such as Richard Middleton have noted the tendency of rock songs to pair sections with distinct harmonic languages, and Lori Burns's analysis of a Tori Amos song proceeds from the premise that "each section of the song explores a different harmonic idiom," which prompts her to "avoid an ultimate Ursatz interpretation," the need for a gauge more precise than the catchall category "nontonal" becomes clear (Middleton 1990, 195-96; Burns 2008, 68).

Example 1 illustrates the type of song alluded to in Everett's quote. "Good Day Sunshine" presents four sections$\mathrm{A}, \mathrm{B}, \mathrm{C}$, and $\mathrm{D}$-and four keys- $\mathrm{B}$ major, $\mathrm{A}$ major, $\mathrm{D}$ major, and $\mathrm{C}$ major-all within the span of two minutes. The final chords of sections $\mathrm{A}$ and $\mathrm{B}$ act as the dominants of the keys of sections $\mathrm{B}$ and $\mathrm{C}$ but do not support an overriding tonic. Naphtali Wagner's analysis of the song supports this portrayal; he analyzes sections $\mathrm{A}$ and $\mathrm{B}$ in different keys but does not comment on sections C or D (Wagner 2003, 362-63). Everett views the song in the same way, stating that "a fourth, nonresolving tonal center is heard when [section D] ascends a half-step from B major" (Everett 1999, 59). For Wagner and Everett, a description of the song as nontonal as per Everett's quote is apt.

However, I propose that "Good Day Sunshine" is a tonal song. It is an instance of what I term sectional tonality. Let us refer to a section as a distinct part of a song's formal structure, such as an intro, verse, bridge, transition, refrain, pre-chorus, chorus, solo, interlude, ending, or coda (Covach 2005). ${ }^{1}$ Then, we can define sectional tonality (hereafter ST) as a type of tonality in which each section projects a distinct key. The keys may or may not be related, and may or may not connect via a pivot chord, but the overall key succession is

I Everett (1999, 315-19) and Stephenson (2002, 133-38) discuss sections in rock songs. 


\begin{tabular}{|c|c|c|c|c|}
\hline \multicolumn{5}{|c|}{ Form: $\mathrm{A}-\mathrm{B}-\mathrm{A}-\mathrm{B}-\mathrm{C}-\mathrm{A}-\mathrm{B}-\mathrm{A}-\mathrm{D}$} \\
\hline Section & Chorus (A) & Verse (B) & Bridge $(\mathrm{C})$ & Coda (D) \\
\hline Key & B major & A major & $\mathrm{D}$ major & $\mathrm{C}$ major \\
\hline Roman & $\mathrm{I}-\mathrm{V}^{7}-\mathrm{IV}^{\mathrm{b} 7}$ & $\mathrm{I}-\mathrm{V}^{7} / \mathrm{V} / \mathrm{V}-\mathrm{V}^{7} / \mathrm{V}-\mathrm{V}^{7}-\mathrm{I}$ & $\mathrm{I}-\mathrm{V}^{7} / \mathrm{V} / \mathrm{V}-\mathrm{V}^{7} / \mathrm{V}-\mathrm{V}^{7}-\mathrm{I}$ & $\mathrm{IV}^{\mathrm{b} 7}$ \\
\hline Numerals & A: $\quad V^{7}$ & $\mathrm{D}:$ & & \\
\hline
\end{tabular}

eXAmple i. The Beatles, “Good Day Sunshine." Written by John Lennon and Paul McCartney. (C) 1966, EMI Records Ltd.

not governed by a single tonic because "closure is not provided by any overall directed voice leading," to reprise Everett's quote. Overall directed voice leading is absent when the keys do not fit a Schenkerian background such as $\mathrm{I}-\mathrm{V}-\mathrm{I}$, arpeggiate a consonant triad, or employ passing, neighboring, or any other voice-leading techniques to raise one key above the others in structural importance. The notion of ST thus hinges on a simple idea, yet one that is radical from the deeply engrained perspective of monotonality. If each section of a song projects tonal harmony, then it is not a stretch to deem the entire song tonal- not monotonal, just tonal. The result is a patchwork tonality of sorts: a section of music in one key, followed by a section in a second key, followed perhaps by a section in a third key, and so on. Such songs are said to be sectionally tonal (also ST).

We can place ST in a broader context by comparing it to other piece-wide gauges of tonality. To this end, Example 2 offers a continuum of tonality gauges. Three points of comparison underlie the gauges: the number of governing keys; whether the keys are equally weighted or not; and whether the first and last keys are the same. At one end of the spectrum is Schoenberg's Monotonality and Schenker's Tonality, in which "all pitch content, including every modulation, no matter how distant, is ultimately subordinate to a single tonic" (Anson-Cartwright 2001, 234). In Implicit Tonality, "a [single] key is invoked but not actually confirmed" (Stein 1997; Baker 1980). In Double Tonality or Tonal Pairing, "two [unequally weighted] keys alternately occupy the highest position in a tonal hierarchy" (Krebs 1996, 18) and "either [tonic] triad of the pair can serve as the local representative of the tonic complex. Within that complex itself, however, one of the two elements is at any moment in the primary position while the other remains subordinate to it" (Bailey 1985, 121-22). In Modified Directional Tonality, two unequally weighted keys appear in succession (Anson-Cartwright 2001, 238; Krebs 1981). In Directional or Progressive Tonality, "one key functions as an opening tonality; and after the first key is clearly established as a tonic, a transformation occurs whereby the initial tonic becomes a nontonic function within a second tonality. The piece then concludes on the second key. The overriding factor is the coexistence in directional tonality of two equally weighted tonal centers within one musical work" (Stein 1985, 143-44). And in ST, no weighted relations among keys and sections factor into the analytic process.

\section{SECTIONAL CENTRICITY}

Many rock songs exhibit a technique akin to ST in which each section presents pitch material other than a major or minor key. The pitch-class content of each section is distinct, with one or more pitch-classes acting as a center/s in each section. I use the term sectional centricity (SC) to describe such songs. Part II of this paper elaborates on the notion of centricity in rock. 
Monotonality/Tonality

(Schoenberg 1969; Schenker 1979)

Implicit Tonality

(Stein 1997; Baker 1980)

Double Tonality/Tonal Pairing

(Krebs 1996; Bailey 1985)

Modified Directional Tonality

(Anson-Cartwright 2001; Krebs 1981)

Directional/Progressive Tonality (Stein 1985)

Sectional Tonality

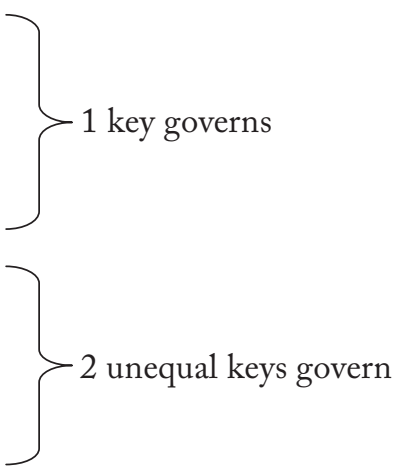

2 equal keys govern; first and last keys are different

2 equal keys govern; first and last keys are the same; or $\geq 3$ keys; no key governs

EXAMPLE 2. Gauges of tonality

My approach to centricity in rock stems from studies by Joseph N. Straus (1990; 2005), Walter Everett (2004), Christopher Doll (2007), and from my earlier work (2004). While Straus's work addresses post-tonal art music, much of it is useful for the analysis of rock as well. One practice I borrow from Straus involves determining the total pc content of a section. Doing so often reveals a 5-cycle set, whose individual pitchclass members occupy adjacent positions on the circle of fifths (Harrison 1997; Headlam 1996, 74-77). Several 5-cycle sets common to post-tonal art music - the pentatonic collection, diatonic hexachord, diatonic collection, and diatonic octad-are common to rock music as well. Gapped 5-cycle sets, whose individual pitch-class members occupy adjacent positions on the circle of fifths with a single gap, are equally common. ${ }^{2} 5$-cycle and gapped 5-cycle sets are capable of producing a variety of contrasting musical effects. On the one hand, Straus emphasizes the ability of the diatonic collection "to create stable harmonic areas" in post-tonal art music, an effect found in rock as well (Straus 1990, 107). On the other hand, Straus observes that, for example, "often [the diatonic octad] is associated not with a single pitch-class center but rather with an ambiguous clash of competing centers" (Straus 1990, 96). Further, Daniel Harrison posits that while " 5 -cycle material in general ([the diatonic collection] in particular) is the stuff from which keys and tonics are made," such sets can also be "deployed so as to avoid creating keys and central tonal points," supporting instead "tonal regions without sure centers" (Harrison 1997, 399-401).

While Straus and Harrison focus on 5-cycle sets containing five through eight pitch-classes, Everett and I study pentatonic segments, two or three note figures drawn from a 
minor pentatonic collection that may function in a number of keys (Capuzzo 2004, 193-96; Everett 2004, §17-24. See also Covach 2004 and Capuzzo 2009). Example 3 depicts the segments, most of which form gapped 5-cycle sets. Pentatonic segments may appear as single-note bass lines, may be harmonized in parallel fifths, or may occur as nonfunctional parallel major triads. ${ }^{3}$ For instance, $\mathrm{C}-\mathrm{B} b-\mathrm{C}$ can suggest the lower neighbor figure $\hat{1}-\hat{\overline{7}}-\hat{1}$ or the rock cadence $\mathrm{I} \rightarrow \mathrm{VII}-\mathrm{I}{ }^{4}$ Similarly, C-E $b-\mathrm{F}$ can allude to scale degrees $\hat{1} \rightarrow \hat{3}-\hat{4}$ or $\hat{5}-\hat{7}-\hat{1}$ of a major or minor key, or can form the rock progressions $\mathrm{I} \rightarrow \mathrm{III}-\mathrm{IV}$ or $\mathrm{V} \rightarrow \mathrm{VII}-\mathrm{I}$.

A second tenet borrowed from Straus is a flexible attitude towards centricity. Straus notes that "there are no strict 'rules' for analyzing centric pieces because the nature of the centricity varies so much from piece to piece" (Straus 1990, 106). A third and final tenet acknowledges the structural overlap of centricity with common-practice tonality while also recognizing its structural independence. To this end, Straus proposes six characteristics of common-practice tonality (major/minor keys; key relations through modulations; diatonic major and minor scales; triads and seventh chords; tonic-predominant-dominant harmonic function; traditional voice-leading norms), then posits that "of these six attributes, the first four characterize a significant body of post-tonal music, although often in nontraditional ways" (Straus 2005, 130). He then elaborates,

All tonal music is centric, focused on specific pitch classes or
triads, but not all centric music is tonal. Even without the re-
sources of tonality, music can be organized around referential
centers. A great deal of post-tonal music focuses on specific

3 Pentatonic segments harmonized with parallel major triads form the basis of Everett's Type 5 rock tonal system, while segments harmonized in parallel fifths form the basis of Type 6a (Everett 2004, §19-24).

4 Doll (2004), Everett (1999, 313), and O’Donnell (2006, 136) discuss bVII-I in rock music, and note that $b \hat{7}$ often acts as a lower neighbor to $\hat{1}$ in this style. pitches, pitch classes, or pitch-class sets as a way of shaping and organizing the music. In the absence of functional harmony and traditional voice leading, composers use a variety of contextual means of reinforcement. In the most general sense, notes that are stated frequently, sustained at length, placed in a registral extreme, played loudly, and rhythmically or metrically stressed tend to have priority over notes that don't have those attributes (Straus 2005, 131; emphasis added).

Straus's remarks apply in large part to centric rock music. In particular, the two italicized criteria-registral extremity and rhythmic or metric stress-can be useful determinants of centricity in rock. ${ }^{5}$

While Doll's work echoes the last sentence of the Straus quote, Doll also acknowledges the role of functional harmonic progressions in the determination of centricity in rock $(2007,64)$. For instance, the major chords C-D-G can suggest $\mathrm{I}-\mathrm{V} / \mathrm{V}-\mathrm{V}$ in $\mathrm{C}, \mathrm{IV}-\mathrm{V}-\mathrm{I}$ in $\mathrm{G}$, bVII-I-IV in $\mathrm{D}$, $b \mathrm{III}-\mathrm{IV} \rightarrow \mathrm{VII}$ in $\mathrm{A}$, or $b \mathrm{VI} \rightarrow \mathrm{VII} \rightarrow \mathrm{III}$ in $\mathrm{E}$. Doll uses such progressions to determine the central pitch-class of several rock songs. He also acknowledges situations in which more than one center is active. Doll uses the term centric ambiguity to account for this situation, in which "the presence of multiple centers (either concurrent or consecutive) can sometimes create disorientation" (Doll 2007, 85). ${ }^{6}$ Centric ambiguity is a fundamental trait of many SC songs: when it is difficult to pinpoint a single center within a section, it is often difficult to pinpoint a single center across sections. For this reason, I shall track voice-leading goals within sections only. The following analyses demonstrate how instrumentation, timbre, lyric content, and tonal allusions work in tandem with SC.

5 Temperley $(2004,330)$ and Stephenson $(2002,37)$ also make this point.

6 "Centric ambiguity" first appears in Straus 1990, 93. See also Boone 1997, 176. 


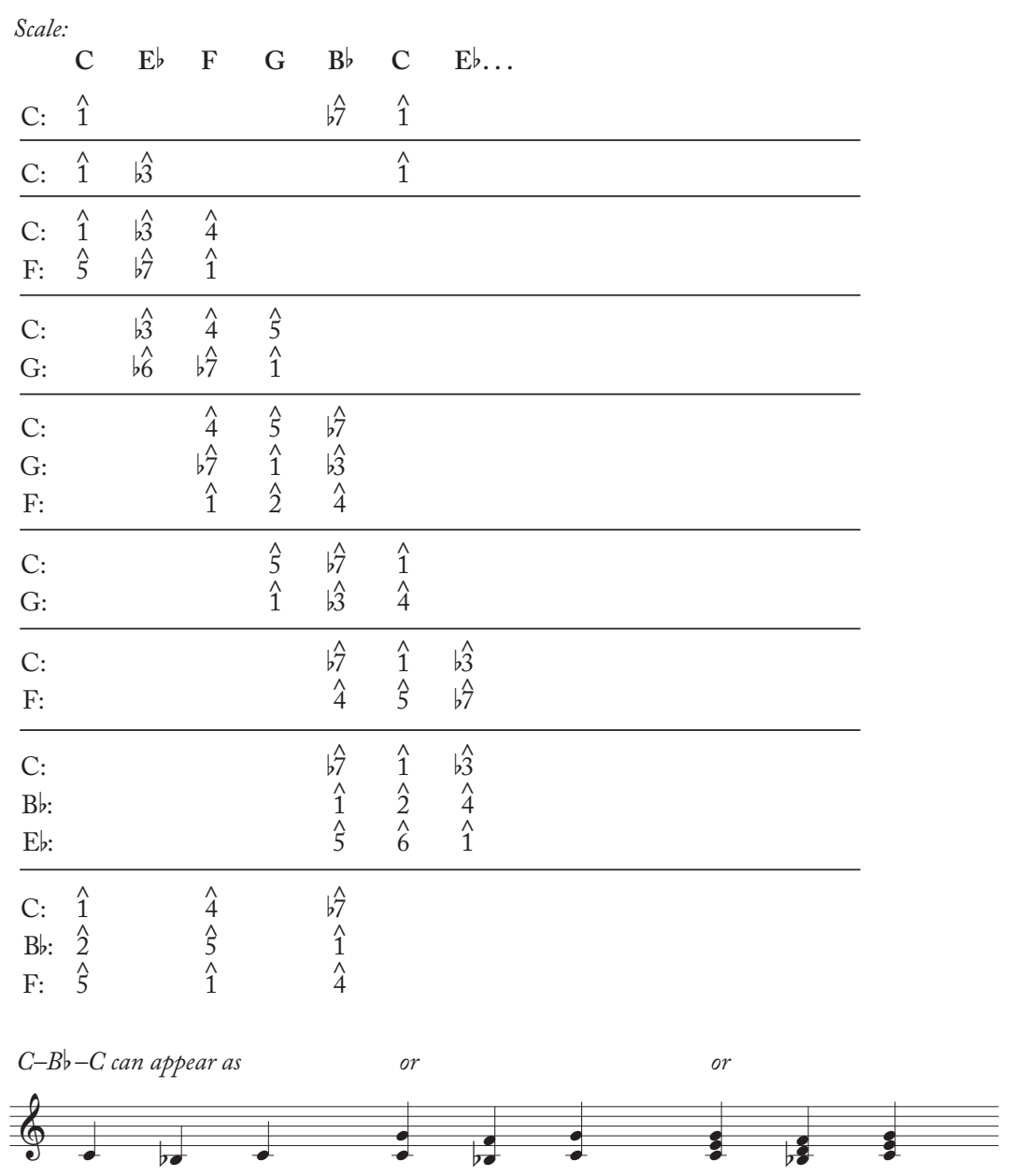

example 3. Pentatonic segments 


\section{ANALYSES}

Radiohead, "Karma Police." Dai Griffiths devotes considerable analytic commentary to "Karma Police"; Examples 4(a)-4(c) provide my transcription of the voice, acoustic guitar, and bass parts (Griffiths 2004, 38-9, 61-64, 92). ${ }^{7}$ His remarks resonate strongly with the features of SC. He observes three distinct keys and calls the song "a story of two sections" (Griffiths 2004, 61). His first section contains the intro/verse (my section A, A minor) and the chorus (my section $\mathrm{B}, \mathrm{E}$ minor), while his second section contains the ending (my section $\mathrm{C}, \mathrm{B}$ minor); the form is $\mathrm{A}-\mathrm{A}-\mathrm{A}-\mathrm{B}-\mathrm{A}-\mathrm{B}-\mathrm{C}$. However, because the song largely lacks functional harmonic progressions, I shall avoid the term "key," and shall substitute the terms "collection" to identify pitch-class content and "center" to identify the focal pitch-class of a given collection.

I view the centers and the number of sections somewhat differently than Griffiths. I take each section to correspond to two or more centers, such that the song has three sections and three sets of centers. Turning first to the centers, A emerges as the center of section A in several ways. Example 4(a) provides a voice-leading reduction of the relevant passage. The reduction proceeds in three stages. Each stage has its own system. The first system includes the bass notes that fall on beats one and three of each measure of the transcription, as well as the vocal notes on beats one, three, and four, and provides more detail in the antepenultimate measure, where parallel octaves underscore the stepwise descent $\mathrm{C}-\mathrm{B}-\mathrm{A}$. The second system shows the bass and vocal notes that occupy the downbeat of each measure, revealing a $\mathrm{i}-\mathrm{v}$ alternation followed by a closing $\mathrm{i} \rightarrow \mathrm{VII}-\mathrm{i}$. The third system depicts an upper voice descent $\mathrm{C}-\mathrm{B}-\mathrm{A}$ above an $\mathrm{A}-\mathrm{G}-\mathrm{A}$

7 I omit the other instruments from the transcriptions as they double notes from the transcribed parts. Some block-chord reductions appear in the interest of clarity. bass. These voice-leading motions create strong allusions to the key of A minor. Other factors contributing to the A centricity include the total pitch-class content of the section, which forms the diatonic octad F-C-G-D-A-E-B-F\#, here understandable as a combination of the A Aeolian and A Dorian collections; the metric emphasis on Am triads, which appear on the downbeats of measures 1, 3, 5, and 7; and the G-Am progressions (measures 2-3 and 4-5), which suggest bVII-i in A minor. ${ }^{8}$ Despite these factors, however, harmonic ambiguity is present: $\mathrm{Em}-\mathrm{G}-\mathrm{Am}-\mathrm{F}$ and $\mathrm{Em}-\mathrm{G}-\mathrm{Am}-\mathrm{D}$ suggest $\mathrm{i}-\mathrm{III}-\mathrm{iv}-\mathrm{II}$ and $\mathrm{i}-\mathrm{III}-\mathrm{iv}-\mathrm{VII}$ in $\mathrm{E}$ minor, although this hearing grates against the hypermetric emphasis on the Am triads. In light of the $\mathrm{E}$ minor allusions, the total pitchclass content of section A may additionally be understood as a combination of the $\mathrm{E}$ Aeolian and $\mathrm{E}$ Phrygian scales. The pentatonic segments $\mathrm{E}-\mathrm{G}-\mathrm{A}$ (measures 2-3 and 4-5) and A-B-D (measures 7-8) also engender harmonic ambiguity since each segment alludes to both $\mathrm{A}$ minor and $\mathrm{E}$ minor. Specifically, E-G-A suggests $\hat{5}-\hat{7}-\hat{1}$ in $A$ minor and $\hat{1}-\hat{3}-\hat{4}$ in $\mathrm{E}$ minor, while $\mathrm{A}-\mathrm{B}-\mathrm{D}$ suggests $\hat{1}-\hat{2}-\hat{4}$ in $\mathrm{A}$ minor and $\hat{4}-\hat{5} \rightarrow \hat{7}$ in $\mathrm{E}$ minor. ${ }^{9}$

I claim $\mathrm{G}$ as the center of section B over Griffiths's choice of the key of $\mathrm{E}$ minor due to the recurring $\mathrm{C}-\mathrm{D} / \mathrm{A}-\mathrm{G}$ progression, or $\mathrm{IV}-\mathrm{V}_{4}^{6}-\mathrm{I}$ in $\mathrm{G}$ major; no tonics or dominants in $\mathrm{E}$ minor appear. But while the $\mathrm{C}-\mathrm{D} / \mathrm{A}-\mathrm{G}$ and $\mathrm{Bm}-\mathrm{D}$ progressions suggest functional $\mathrm{G}$ major harmony, the treatment of ${ }_{4}^{6}$ chords with $\mathrm{D} / \mathrm{A}-\mathrm{G}$ and $\mathrm{Bm} / \mathrm{F} \#-\mathrm{C}$ does not, and for these reasons I prefer to cast section $\mathrm{B}$ in terms of centricity, not

8 The phrase "here understandable as" is important. In the present context, F-C-G-D-A-E-B-F\# makes possible the allusions to A Aeolian, A Dorian, and A minor. In a different context, the same collection might form the backdrop for alternations between, say, G Ionian and $G$ Mixolydian. See Temperley 2004, 313 and Straus 1990, 96-97.

9 Doll $(2007,87 f f$.), uses the term perfect centric ambiguity to refer to ambiguity between centers whose roots are a perfect fourth or perfect fifth apart, as in Example 4(a). 

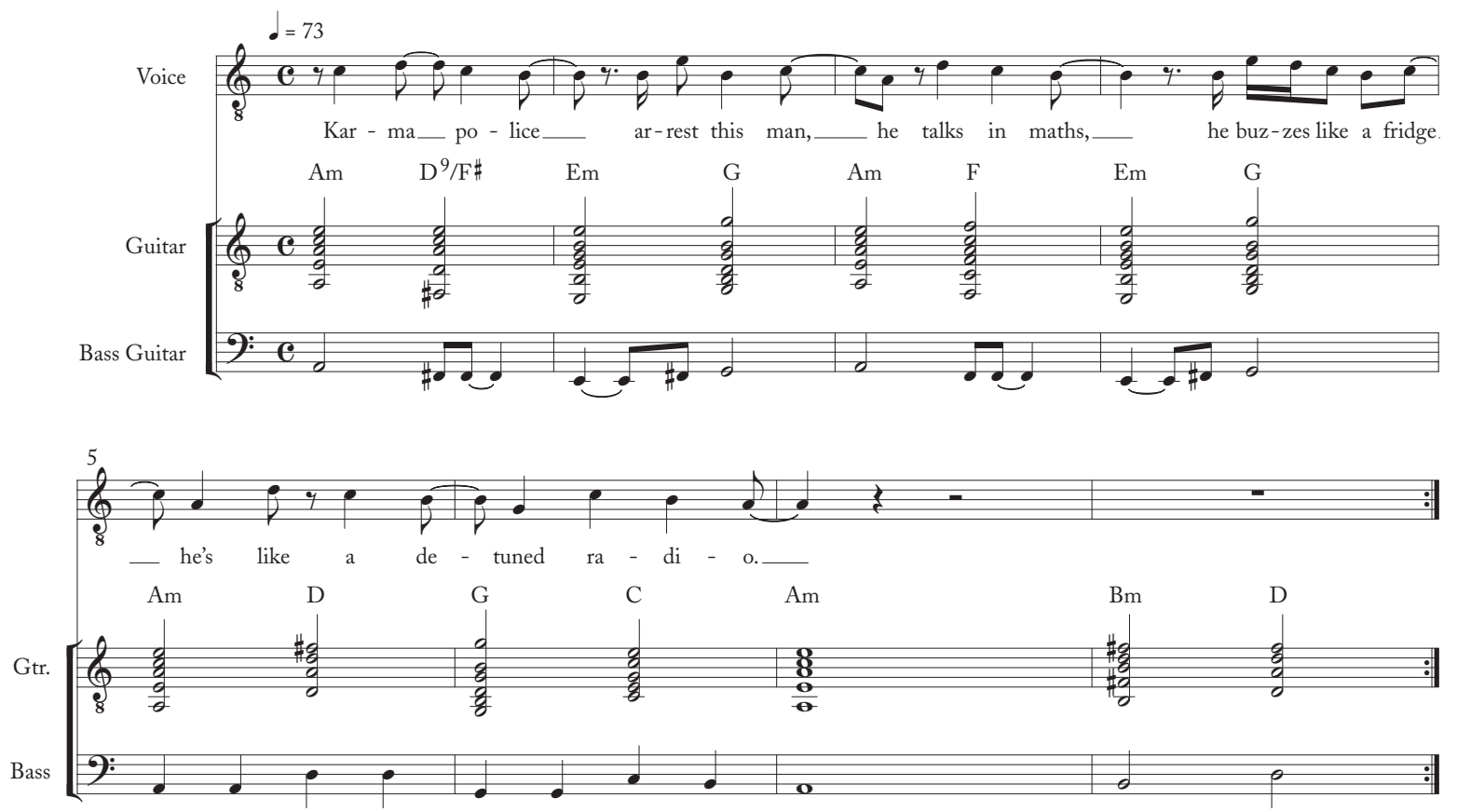

example 4(A). Radiohead, "Karma Police," section A. Written by Thomas Yorke, Jonathan Greenwood, Philip Selway, Colin Greenwood, and Edward O'Brien. (C1997, EMI Records Ltd.

tonality. ${ }^{10}$ The tritone motions from $\mathrm{F} \#$ to $\mathrm{C}$ also challenge the references to $\mathrm{G}$ major, and complement the mockthreatening tone of the lyrics: "This is what you get when you mess with us." ${ }^{11}$ There are allusions to B minor as

No pitches from other instruments appear below the ${ }_{4}^{6}$ chords to create ${ }_{3}^{5}$ chords.

II I say mock-threatening because Radiohead vocalist, guitarist, and cosongwriter Thom Yorke has emphasized the tongue-in-cheek nature of the song (Doheny 2002, 71). well: $\mathrm{G}-\mathrm{F} \#$ suggests bVI-V and Bm-D suggests $\mathrm{i}-\mathrm{III}$. The total pitch-class content of section $\mathrm{B}$ is the gapped 5-cycle set $A \#-(F)-C-G-D-A-E-B-F \#-C \#$, here understandable as a combination of a $G$ Ionian scale $(A \#-(F)-$ C-G-D-A-E-B-F\#-C\#), a B Aeolian scale (A\#-(F)$\mathrm{C}-\mathrm{G}-\mathrm{D}-\mathrm{A}-\mathrm{E}-\mathrm{B}-\mathrm{F} \#-\mathrm{C} \#)$, and an $\mathrm{F} \#$ major triad $(\underline{A} \sharp-(\mathrm{F})-$ $\mathrm{C}-\mathrm{G}-\mathrm{D}-\mathrm{A}-\mathrm{E}-\mathrm{B}-\mathrm{F} \#-\mathrm{C} \#)$. Example 4(b) offers two voiceleading reductions of the $\mathrm{B}$ section. The first system pairs every bass note in the $\mathrm{B}$ section with the vocal notes above them, allowing for some rhythmic normalization. The second 

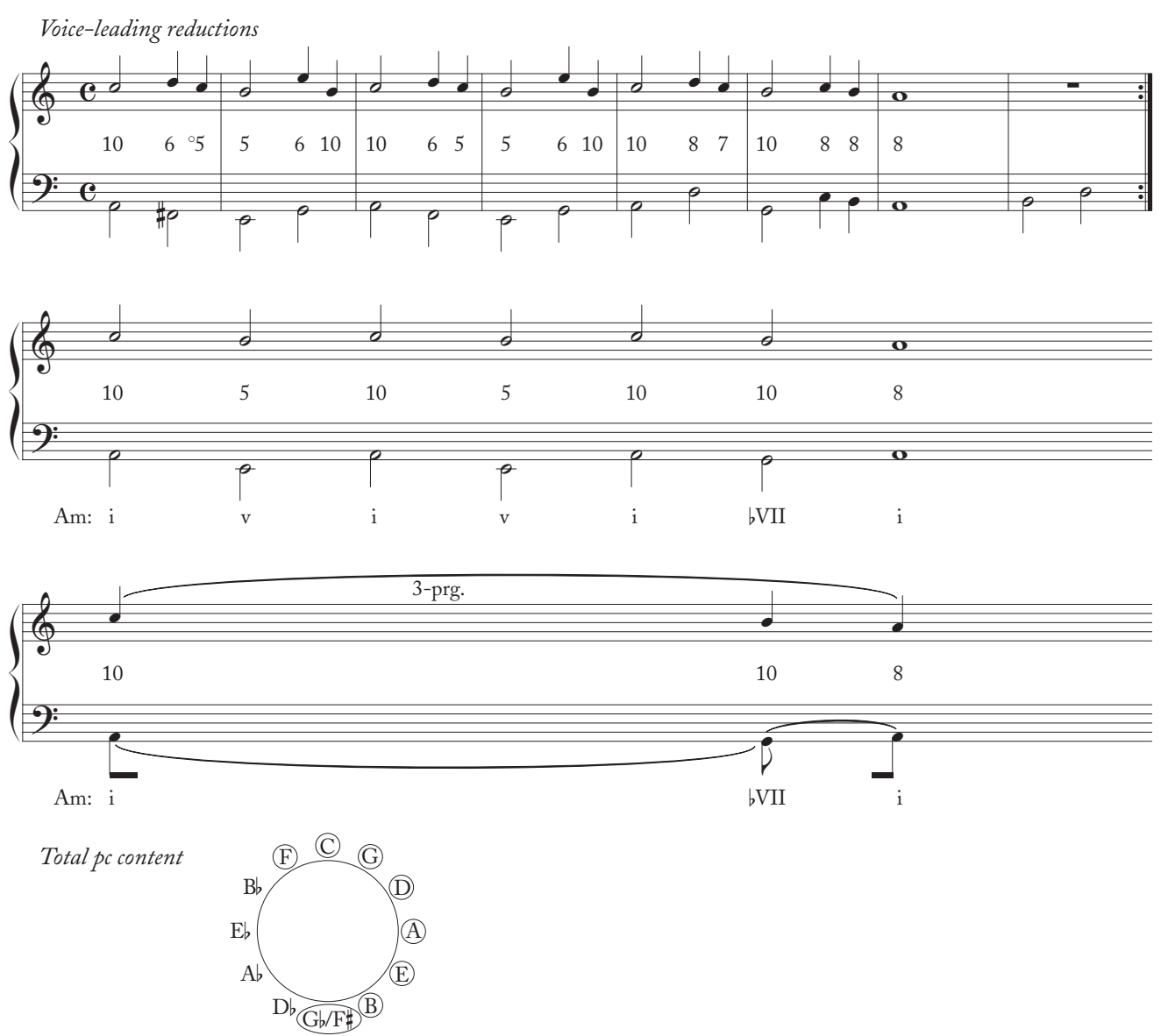

\section{EXAMPLE 4(A). [continued]}

system offers an interpretation of the $G$ centricity that reveals the harmonic progression $\mathrm{I}-\mathrm{iii}-\mathrm{V}$.

The $\mathrm{Bm}-\mathrm{D}$ progression that closes sections $\mathrm{A}$ and $\mathrm{B}$ opens section $\mathrm{C}$. Save for a missing $\mathrm{C} \#$, the pitch-class content of section $\mathrm{C}$ transposes by 2 semitones the pitch-class content of section A. Example 4(c) shows how section $\mathrm{C}$ gathers the keys alluded to in sections $\mathrm{A}$ and $\mathrm{B}$ : section $\mathrm{C}$ alludes to $A$ minor and $E$ minor in the $A$ section and $G$ major and $\mathrm{B}$ minor in section $\mathrm{B}$. In addition, section $\mathrm{C}$ alludes to $\mathrm{D}$ major by means of $\mathrm{G}-\mathrm{D}$ plagal motions and the suggestion of $\hat{3}-\hat{2}-\hat{1}$ in the opening $F \#-E-D$ melody. The G-D-E motion suggests the pentatonic segment 

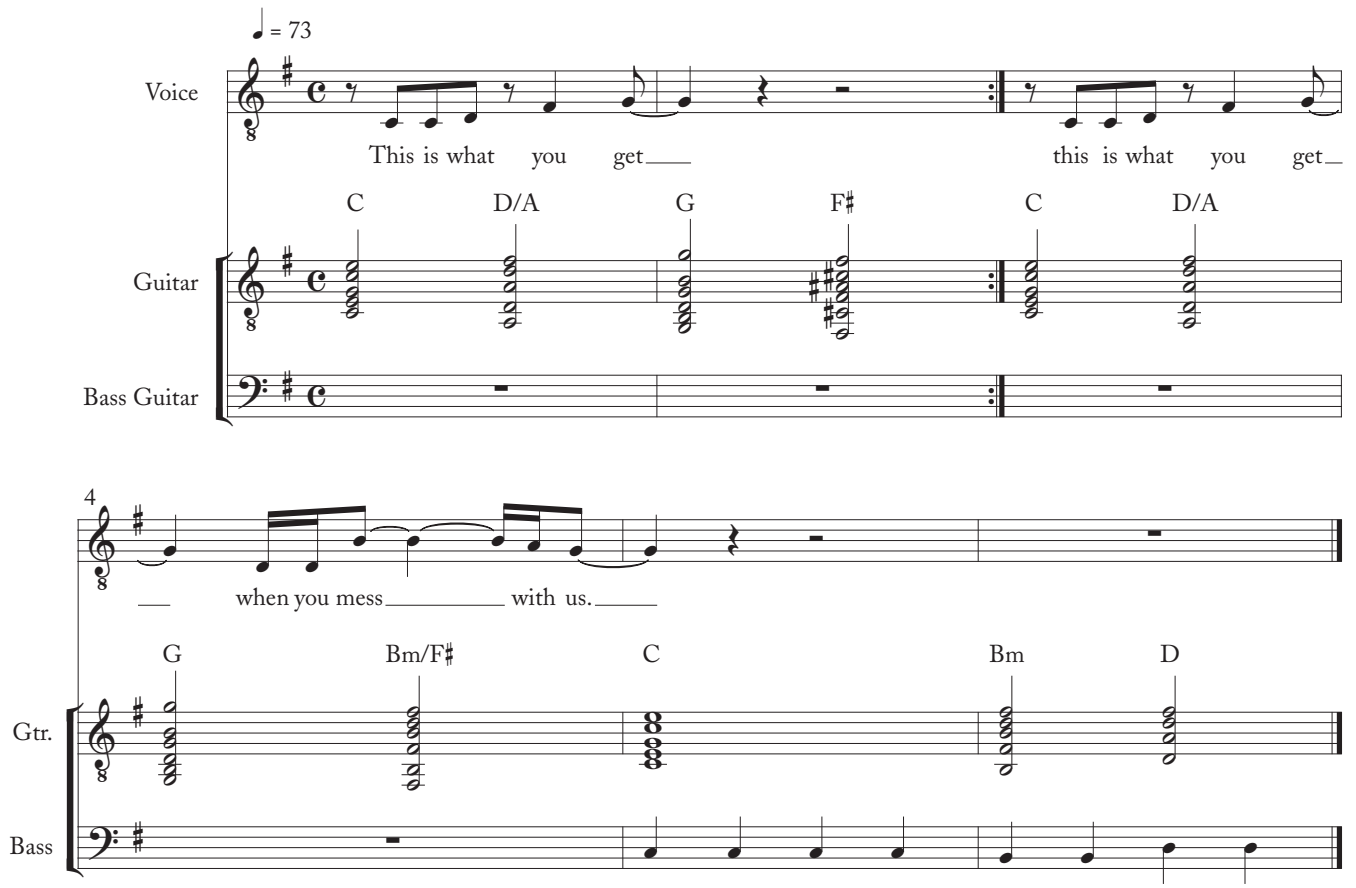

eXample 4(в). Radiohead, "Karma Police," section B. Written by Thomas Yorke, Jonathan Greenwood, Philip Selway,

Colin Greenwood, and Edward O'Brien. (C) 1997, EMI Records Ltd.

$b \mathrm{III} \rightarrow \mathrm{VII}-\mathrm{I}$ in $\mathrm{E}$ minor, and a barely audible $\mathrm{E}$ chord at $4^{\prime} 19^{\prime \prime}$ suggests dominant function in A minor, a key alluded to in the A section. ${ }^{12}$ The metric stress on $\mathrm{Bm}$ (which falls on the downbeat of the first measure of a repeating fourmeasure unit), and the prominence of $\mathrm{Bm}$ as a sustained triad near the end of the song (at $4^{\prime} 03^{\prime \prime}$ help suggest the B center, as does hearing the opening $\mathrm{F} \#-\mathrm{E}-\mathrm{D}$ melody as
5- $-\hat{4}-\hat{3}$. The reductions in Example 4c depict a $\mathrm{B}$ minor reading (i-III-IV-i).

I parse the song into three sections rather than two as Griffiths does. My parsing acknowledges the three-part verse-chorus-ending organization, the separate centers in each section, and the change of lyrical voice in each section. In the first and second verses of the A section an outsider delivers the lyrics: "Karma Police, arrest this man." In section $\mathrm{B}$, a presumed member of the Karma Police issues a threat to the subject: "This is what you get when you mess 
Voice-leading reductions
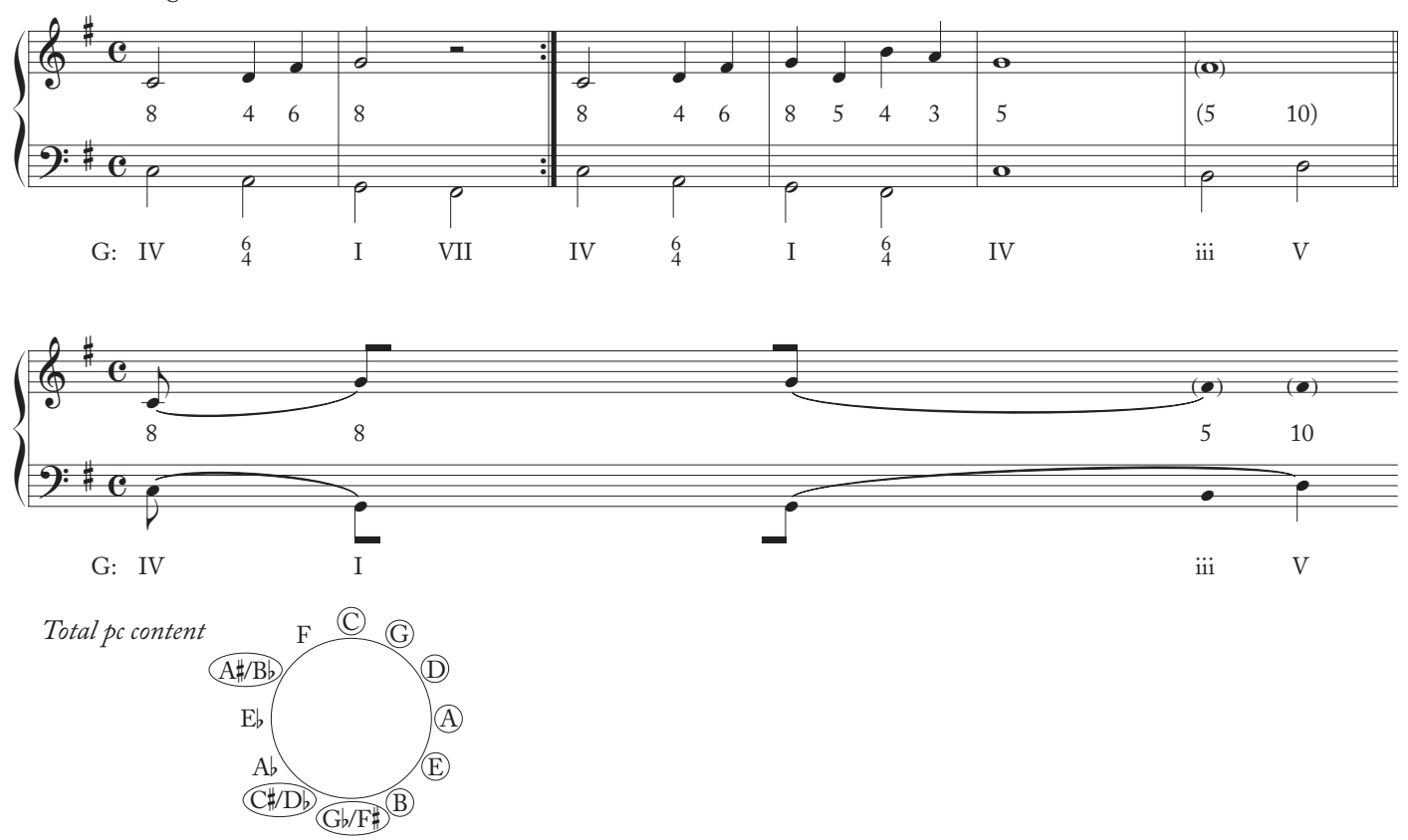

EXAMPLE $4(\mathrm{~B})$. [continued]

with us." In the $\mathrm{C}$ section, the subject wakes from a reverie: "Phew, for a minute there, I lost myself." 13 The music video for "Karma Police" also supports the three-section organization. During section A, a driverless car pursues a running man. Just before the onset of the B section, vocalist Thom Yorke appears in the backseat of the car, curiously lip-synching only some of the lyrics. The repetitions of sections $A$ and $\mathrm{B}$ are set to similar scenes. With the arrival of the $\mathrm{C}$ section, we see the running man's face for the first time. He loses his breath, falls to the ground, spots a trail of gasoline leaking

I3 From this perspective, the third verse is ambiguous: "Karma Police, I've given all I can, it's not enough, I've given all I can, but we're still on the payroll." from the car, lights a match to the gasoline, and watches the car burst into flames. ${ }^{14}$

King's X, "Julia." Co-songwriter, bassist, and vocalist Doug Pinnick states:

'The song 'Julia' comes in two parts. The first part is about when my sister was living with me with a child who was three, and she was twenty-two. Her child began calling me 'Grandpa Dad,' and then she moved back to Illinois and well, the first part is about her leaving and it's my feelings. The chorus is 'Julia, you don't have to cry, I'll do anything you want, be your also discuss the video. 




example 4(c). Radiohead, "Karma Police," section C. Written by Thomas Yorke, Jonathan Greenwood, Philip Selway, Colin Greenwood, and Edward O'Brien. () 1997, EMI Records Ltd.

Superman,' and that doesn't make any sense, but the melody, the music, and the way it goes is just really beautiful. The second part is about a real good friend of mine that had his wife leave him, and it's about her. Julia is really no one, when I got to the chorus all I could hear was this chorus in my head going 'Joo-lee-aa' (singing) and everyone was like, 'Who's Julia?' I said, 'No one! It just sounds so good,' so I left it like that!" (Leach 2000). ${ }^{15}$

From Pinnick's comments, we can glean a few observations on the relationship between lyric content and the song's two parts and four sections. The form is $\mathrm{A}-\mathrm{B}-\mathrm{A}-\mathrm{B}-\mathrm{C}-\mathrm{D}-\mathrm{C}-\mathrm{B}$. Pauses between most sections raise the status of each section to that of a self-standing unit. Part 1 contains the verse (section A) and chorus (section B). The quiet clean-tone guitars

There is no video for "Julia." Similarities exist between the lyrics of "Julia" by King's X and "Julia" by the Beatles; on the latter song, see Everett 1999, 171. and slow tempo of the A section create a serene atmosphere that befits the vocalist's reminiscing about his sister and the child. A steady eighth-note pulse in the bass guitar and bass drum and the introduction of triads then set off section B. Part 2 contains the interlude (section $\mathrm{C}$ ) and bridge (section D). These sections contrast sharply with those of Part 1. Alternating meters combine with loud, distorted, low-register power chords, pounding drums, and an absence of vocals to set the $\mathrm{C}$ section off, while section $\mathrm{D}$ introduces a higher vocal register and what guitarist and co-songwriter Ty Tabor calls a "wobble" effect on the guitar and voice (Blackett 2000). The changes in timbre, dynamics, register, and, as we shall see, pitch material, thus go hand in hand with the change in lyric content from Part 1 to Part 2.

Only Part 2 of "Julia" features clear tonal centers; those in Part 1 are ambiguous at best. In Example 5(a), mild emphasis accrues on pitch-class $\mathrm{E}$ through metric placement-E falls on the downbeat of measure one of a repeating two-measure 


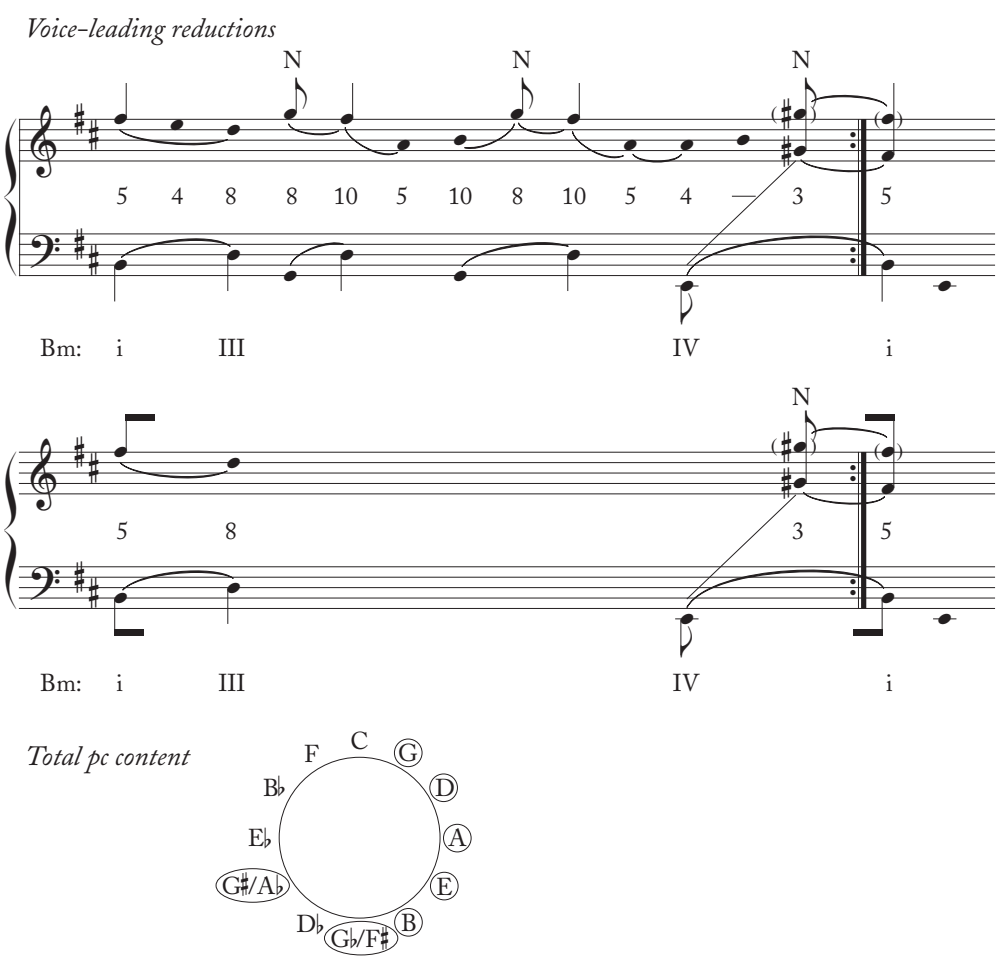

EXAMPLE 4(c). [continued]

unit - and through the E-D-E lower neighbor figure in the voice (measure 1) and strings (measures 1-3), which suggests $\hat{1} \rightarrow \hat{7}-\hat{1}$ in $E{ }^{16}$ At the same time, pitch-class $A$ receives emphasis through registral placement $\left(A_{0}\right.$ is the lowest pitch of section $A$ ), metric placement (it falls on the downbeat of measures 2, 4, 6, and 8), arpeggiation (the bass arpeggiates an Am triad from measure 1 to measure 2), and the $\{A, B$, E\} chord that closes the section. No clear-cut center
The guitar and bass are unconventionally tuned to $A_{1}-E_{2}-A_{2}-D_{3}-F_{3}-B_{3}$ and $\mathrm{A}_{0}-\mathrm{E}_{1}-\mathrm{A}_{1}-\mathrm{D}_{2}$ respectively. emerges; the total pitch-class content is the diatonic hexachord $\mathrm{C}-\mathrm{G}-\mathrm{D}-\mathrm{A}-\mathrm{E}-\mathrm{B}$. The voice-leading reduction in Example 5(a) indicates three motives found in the A section and throughout the song: the aforementioned lower neighbor figure ("LN") E-D-E, a descending-thirds motive

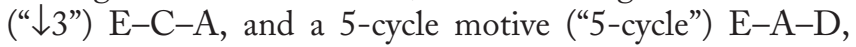
which suggests scale degrees $\hat{1}-\hat{4}-\hat{7}$ in $\mathrm{E}$ and $\hat{5}-\hat{1}-\hat{4}$ in $\mathrm{A}$. The reduction would look very much the same if it were to portray $\mathrm{A}$ as the center instead of $\mathrm{E}$. In contrast to the diatonic hexachord in section A, Example 5(b) indicates that every pitch-class except $F \sharp / G$ b appears in section $B$, thus 

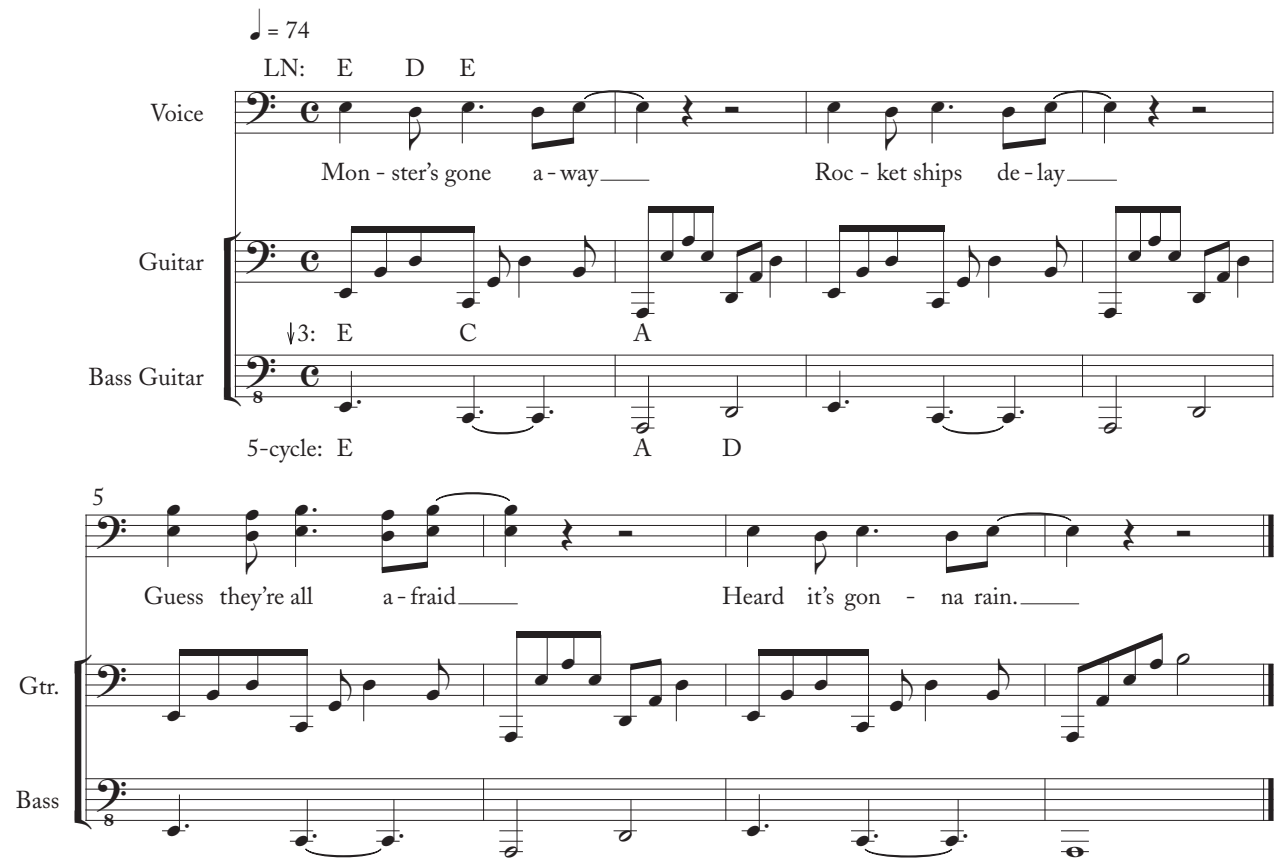

Voice-leading reduction
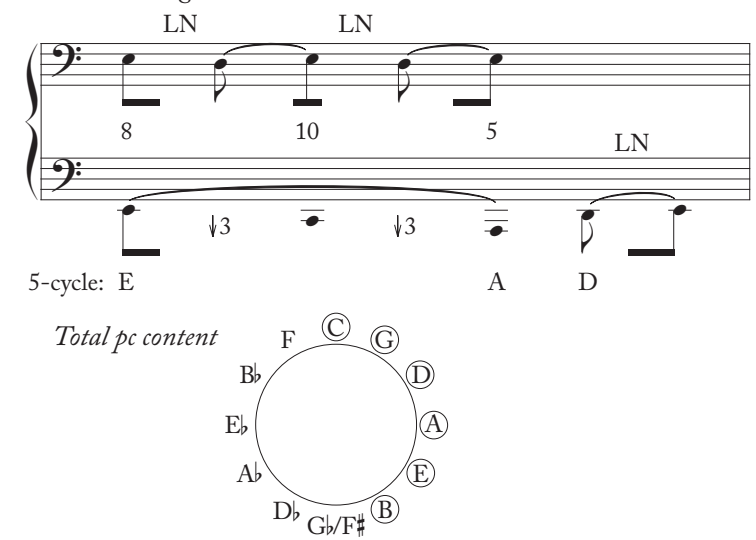

example 5(A). King's X, "Julia," section A. Written by Jerry Gaskill, Doug Pinnick, and Ty Tabor. (C) 2000 Groove Ulysses Music, ASCAP. 

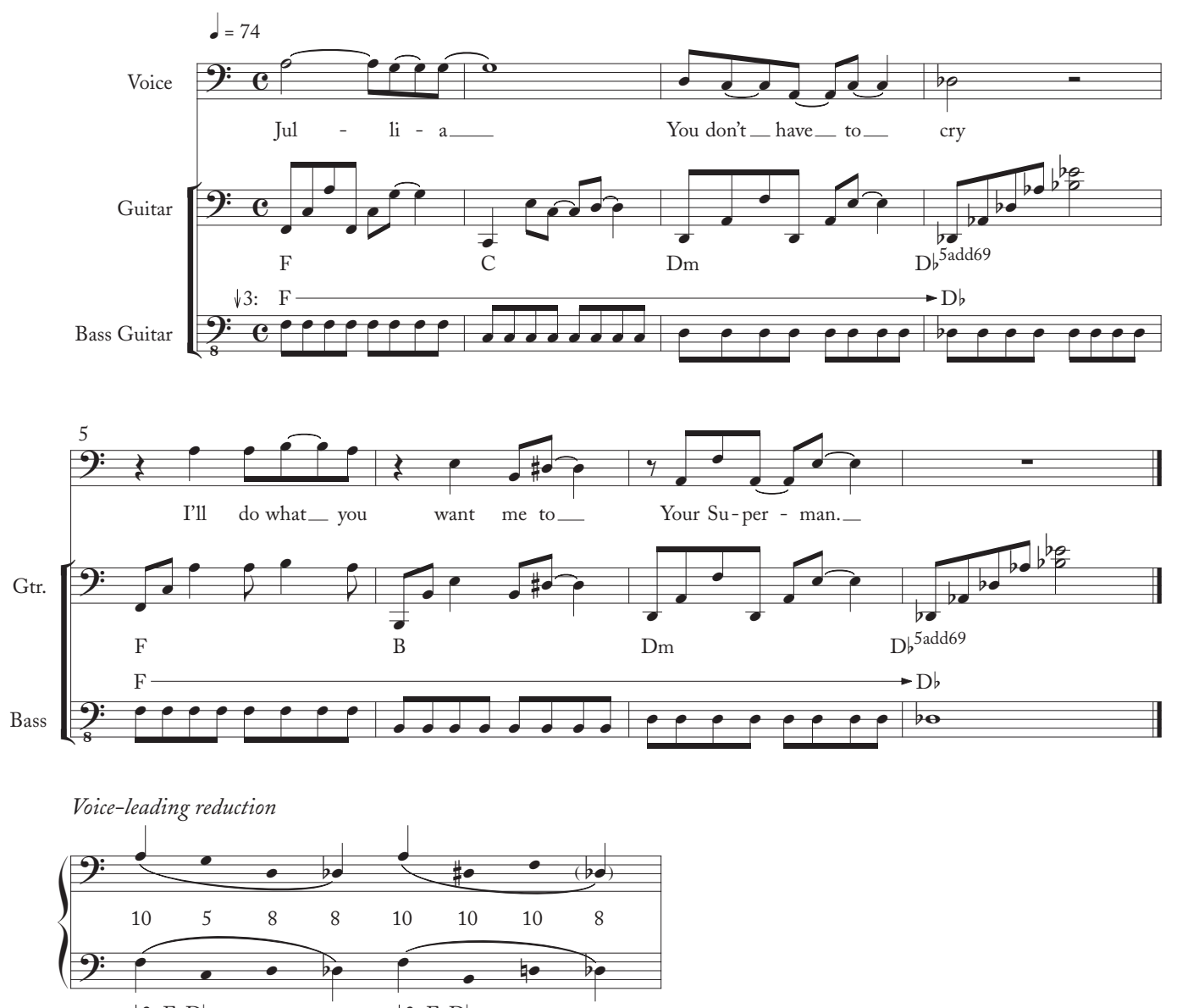

$\downarrow 3 \mathrm{~F}-\mathrm{D} b$

$\downarrow 3 \mathrm{~F}-\mathrm{D} b$

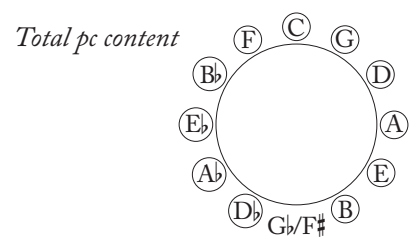

example 5(в). King's X, "Julia," section B. Written by Jerry Gaskill, Doug Pinnick, and Ty Tabor. (C) 2000 Groove Ulysses Music, ASCAP. 


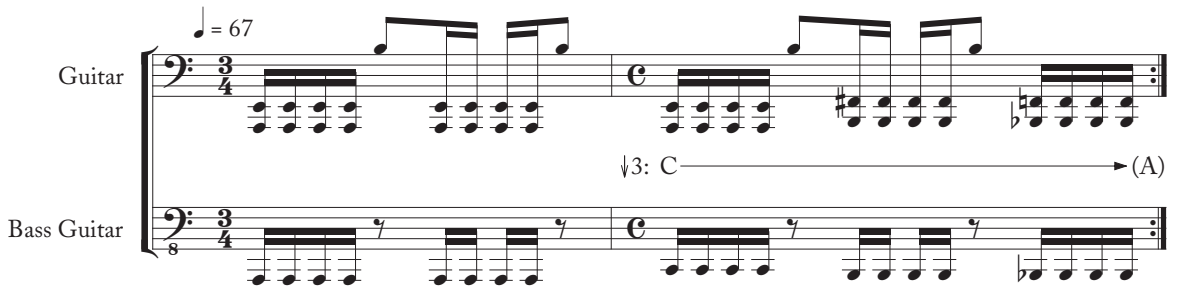

Voice-leading reduction
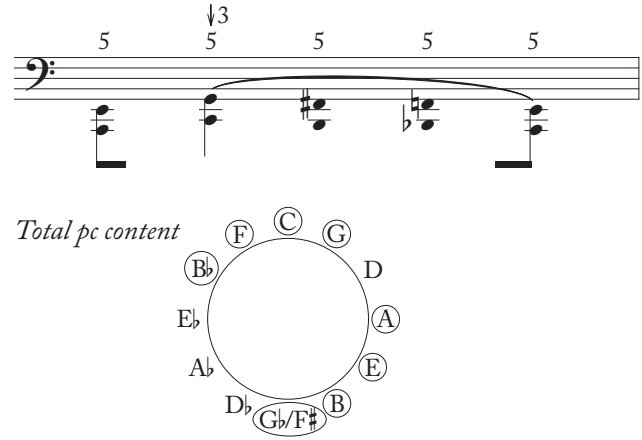

example 5(c). King's X, "Julia," section C. Written by Jerry Gaskill, Doug Pinnick, and Ty Tabor.

(C) 2000 Groove Ulysses Music, ASCAP.

creating a 5-cycle set of eleven pitch-classes. Due to the $\mathrm{F}-\mathrm{C}-\mathrm{Dm}$ progression (measures $1-3$ ), it is possible to hear the opening of section $\mathrm{B}$ in $\mathrm{F}$ major, $\mathrm{C}$ major, or $\mathrm{D}$ minor, but any key is a stretch in light of the tritone motion from $\mathrm{F}$ to B (measures 5-6). Slurs and stems in the voice-leading reduction indicate an equal division of the octave into major thirds $(\mathrm{D} b-\mathrm{F}-\mathrm{A})$, thus carrying the descending-thirds motive into section $\mathrm{B}$.

In section $\mathrm{C}$, registral and metric emphasis mark pitchclass $A$ as the center. Example 5(c) shows that $A_{0}$ is the lowest pitch of the $\mathrm{C}$ section; occupies the downbeat of measure 1 ; and is approached by a version of the descending-thirds motive from $\mathrm{C}_{1} \cdot{ }^{17}$ The pitch-class content of the $\mathrm{C}$ section is the gapped 5-cycle set $\mathrm{B} b-\mathrm{F}-\mathrm{C}-\mathrm{G}-(\mathrm{D})-\mathrm{A}-\mathrm{E}-\mathrm{B}-\mathrm{F}$, which appears on the musical surface as a chromatic tetrachord on $A$ harmonized in parallel fifths $\left(A-B b-B_{4}-C\right.$ and $\mathrm{E}-\mathrm{F}-\mathrm{F} \#-\mathrm{G})$. In Example 5(d), metric emphasis marks $A$ as the center of section $D$, as do 10-6 voice exchanges and a reference to functional harmonic syntax: $A-A / C \#-D^{5}-G^{\text {add } 9}$

I7 I have notated the meter in the $C$ section as $3 / 4$ then $4 / 4$, but other possibilities exist, such as $7 / 4$, or $4 / 4$ then $3 / 4$, or four measures of $3 / 8$ and a measure of $2 / 8$. 


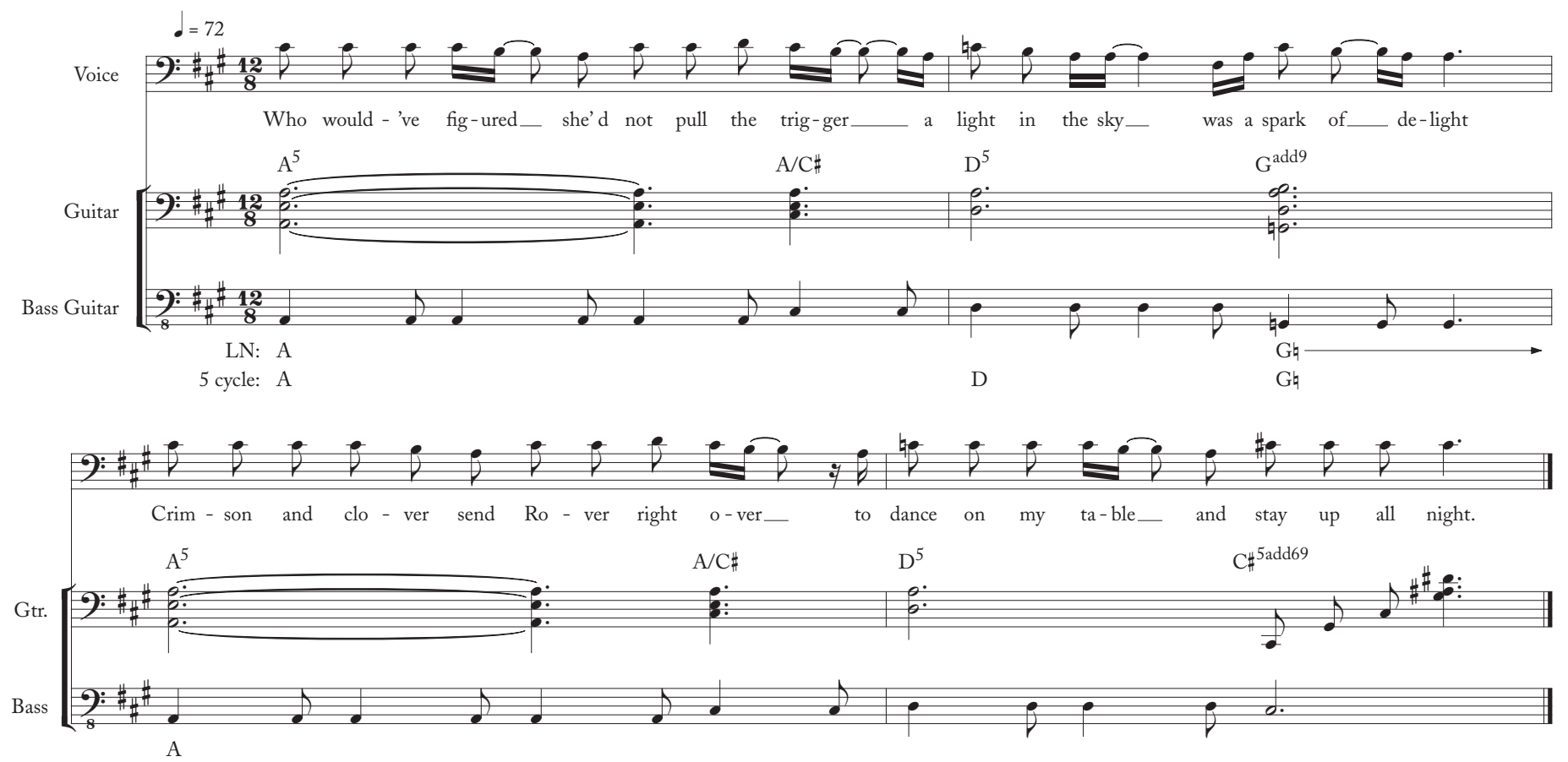

example 5(D). King's X, "Julia," section D. Written by Jerry Gaskill, Doug Pinnick, and Ty Tabor.

(C) 2000 Groove Ulysses Music, ASCAP.

suggests $\mathrm{I}-\mathrm{I}^{6}-\mathrm{IV} \rightarrow \mathrm{VII}$ in A major. The voice-leading reduction in Example 5(d) clarifies this reference to A major and indicates the presence of the 5-cycle motive (here A-D-G suggesting $\hat{1}-\hat{4}-\overrightarrow{7})$, the $L N$ motive (here $A-G b_{k} A$, suggesting $\hat{1} \rightarrow \hat{7}-\hat{1}$ ), and the descending-thirds motive (here $\mathrm{C} \#-\mathrm{A}$ and $\mathrm{C}_{\mathfrak{k}}-\mathrm{A}$ in the voice).

While $\mathrm{A}$ is the center of sections $\mathrm{C}, \mathrm{D}$, and debatably A, the rampant chromaticism of section $B$ all but cancels out an argument for $\mathrm{A}$ as the center of the entire song. At best, one could identify an equal division of the octave by major thirds: $A$ in section $A, F-D$, in section $B, A$ in section $C$, and $A-C \#$ in section $D$. However, while $A$ is a center in sections $\mathrm{C}$ and $\mathrm{D}, \mathrm{F}$ and $\mathrm{D} b$ are merely chord roots in section $\mathrm{B}$ (as is $\mathrm{A}$ in section A). A further complication arises from the song's conclusion in section $\mathrm{B}$, which excludes the A center. Ultimately, a SC reading of the song is more defensible: distinct pitch-class collections, the absence or presence of clear pitch-class centers, and timbre and dynamic changes collectively reinforce the lyrical and sectional organization of "Julia" described by Pinnick. 
Voice-leading reduction

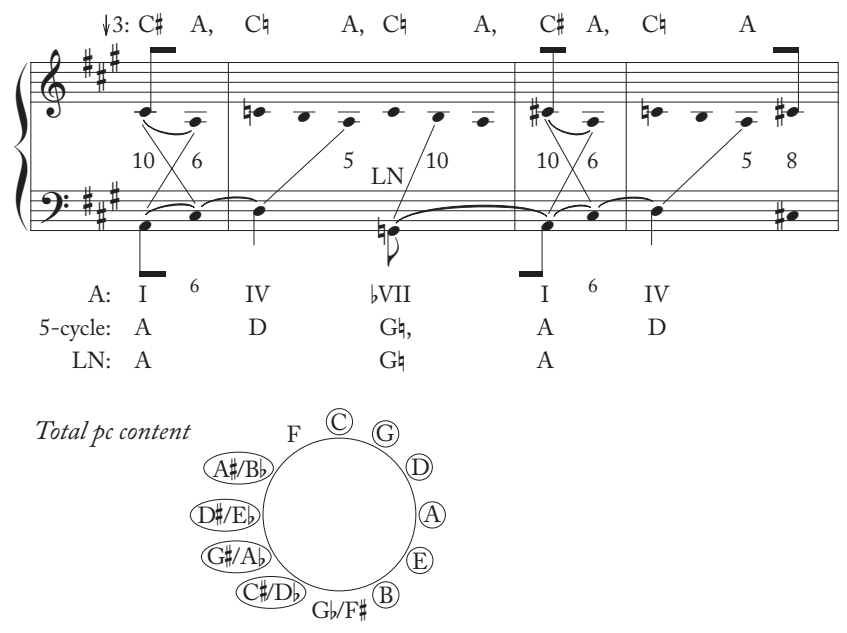

EXAMPLE 5(D). [continued]

REFERENCES

\section{I: Books and Articles}

Anson-Cartwright, Mark. 2001. "Chasing Rainbows: Wolfs 'Phänomen' and Ideas of Coherence." Journal of Music Theory 45.2:233-61.

Bailey, Robert. 1985. "An Analytical Study of the Sketches and Drafts." In Prelude and Transfiguration from "Tristan and Isolde," ed. Robert Bailey, 113-46. New York: W.W. Norton.

Baker, James. 1980. “Scriabin's Implicit Tonality.” Music Theory Spectrum 2:1-18.

Blackett, Matt. 2000. “King's X Guitarist Ty Tabor Keeps the Faith." http:www.guitarplayer.com/archive/artists. kingsx.shtml.

Boone, Graeme. 1997. "Tonal and Expressive Ambiguity in 'Dark Star'." In Understanding Rock: Essays in Musical
Analysis, ed. John Covach and Graeme Boone, 171-210. New York: Oxford University Press.

Burns, Lori. 2008. "Analytic Methodologies for Rock Music: Harmonic and Voice-Leading Strategies in Tori Amos's 'Crucify'." In Expression in Pop-Rock Music, 2nd ed. Ed. Walter Everett, 63-92. New York: Routledge.

Capuzzo, Guy. 2004. "Neo-Riemannian Theory and the Analysis of Pop-Rock Music." Music Theory Spectrum 26.2:177-99.

—. 2009. "A Pedagogical Approach to Minor Pentatonic Riffs in Rock Music." Journal of Music Theory Pedagogy 23.

Covach, John. 2004. "Jimi Hendrix and the Pentatonic Experience." Paper presented to the Society for Music Theory, Seattle.

—_. 2005. "Form in Rock Music: A Primer." In Engaging Music: Essays in Music Analysis, ed. Deborah Stein, 65-76. New York: Oxford University Press.

Doheny, James. 2002. Radiohead: Back to Save the Universe. New York: Thunder's Mouth Press.

Doll, Christopher. 2004. "Rogue Dominants in the Music of Radiohead." Paper presented to the Eighth International Conference on Music Perception, Northwestern University.

2007. "Listening to Rock Harmony." PhD diss., Columbia University.

Everett, Walter. 1999. The Beatles as Musicians: Revolver through the Anthology. New York: Oxford University Press.

2004. "Making Sense of Rock's Tonal Systems." Music Theory Online 10.4.

- 2008. "Pitch Down the Middle." In Expression in Pop-Rock Music, 2nd ed., ed. Walter Everett, 111-74. New York: Routledge.

Griffiths, Dai. 2004. OK Computer. New York: Continuum.

Hainge, Greg. 2005. "To(rt)uring the Minotaur: Radiohead, Pop, Unnatural Couplings, and Mainstream Subversion.” 
In The Music and Art of Radiohead, ed. Joseph Tate, 62-84. Aldershot: Ashgate.

Harde, Erin. 2005. "Radiohead and the Negation of Gender." In The Music and Art of Radiohead, ed. Joseph Tate, 52-61. Aldershot: Ashgate.

Harrison, Daniel. 1997. "Bitonality, Pentatonicism, and Diatonicism in a Work by Milhaud." In Music Theory in Concept and Practice, ed. J. Baker, D. Beach, and J. Bernard, 393-408. Rochester: University of Rochester Press.

2004. "Atalanta in a T-Bird: Directional Tonality in Rock Music." Paper presented to the Experience Music Project on Popular Music, Seattle.

Headlam, Dave. 1996. The Music of Alban Berg. New Haven: Yale University Press.

Krebs, Harald. 1981. "Alternatives to Monotonality in Early Nineteenth-Century Music." Journal of Music Theory 25.1:1-16.

. 1996. "Some Early Examples of Tonal Pairing: Schubert's 'Meeres Stille' and 'Der Wanderer'." In The Second Practice of Nineteenth-Century Tonality, ed. William Kinderman and Harald Krebs, 17-33. Lincoln: University of Nebraska Press.

Leach, Lee Ann. 2000. "The Ever-Enduring Integrity of King's X.” http://kingsx.net/band/articles/ink1962000.shtml.

Mazullo, Mark. 1999. "Authenticity in Rock Music Culture.” PhD diss., University of Minnesota.

Middleton, Richard. 1990. Studying Popular Music. Buckingham: Open University Press.

O’Donnell, Shaugn. 2006. Review of Ken Stephenson, What to Listen for in Rock: A Stylistic Analysis. New Haven: Yale University Press: 2002. Music Theory Spectrum 28.1: 132-40.

Ricci, Adam. 2000. "A 'Hard Habit to Break': The Integration of Harmonic Cycles and Voice-Leading Structure in Two Songs by Chicago." Indiana Theory Review 21:129-46.
Schenker, Heinrich. 1979. Free Composition (Der freie Satz). Translated and edited by Ernst Oster. New York: Longman.

Schoenberg, Arnold. 1969. Structural Functions of Harmony. Rev. ed. New York: Norton.

Stein, Deborah. 1985. Hugo Wolf's Lieder and Extensions of Tonality. Ann Arbor: UMI Research Press.

— 1997. "The Ambiguity Principle: A New Paradigm for Tonality." Paper presented to the Music Theory Society of New York State, Rochester.

Stephenson, Ken. 2002. What to Listen for in Rock: A Stylistic Analysis. New Haven: Yale University Press.

Straus, Joseph N. 1990. Introduction to Post-Tonal Theory, 1st ed. Englewood Cliffs: Prentice Hall.

- 2005. Introduction to Post-Tonal Theory, 3rd ed. Upper Saddle River: Pearson Prentice Hall.

Temperley, David. 2004. "Communicative Pressure and the Evolution of Musical Styles." Music Perception 21/3: 313-37.

Wagner, Naphtali. 2003. “'Domestication' of Blue Notes in the Beatles' Songs.” Music Theory Spectrum 25.2:353-65.

II: Recordings

The Beatles. 1966. "Good Day Sunshine.” Written by John Lennon and Paul McCartney. (c) EMI Records Ltd. Revolver. EMI CDP 7464412.

King's X. 2000. "Julia.” Written by Jerry Gaskill, Doug Pinnick, and Ty Tabor. (C) Groove Ulysses Music, ASCAP. Please Come Home . . Mr. Bulbous. Metal Blade 3984-14298-2.

Radiohead. 1997. "Karma Police." Written by Thomas Yorke, Jonathan Greenwood, Philip Selway, Colin Greenwood, and Edward O'Brien. (c) EMI Records Ltd. OK Computer. 724385522925. 


\section{Contributors}

Eytan Agmon teaches in the Department of Music of BarIlan University, Israel.

matt baileyshea is Assistant Professor at the University of Rochester.

fernando benadon is Assistant Professor of Music at American University.

guY CAPUzzo is Associate Professor of Music at the University of North Carolina-Greensboro.

RICHARD Domek is Professor of Music at the University of Kentucky.

yayoi uno eVerett is currently Associate Professor at Emory University in Atlanta, GA. Her research focuses on the analysis of postwar art music through the perspectives of cultural studies, semiotics, and East Asian aesthetics. Her recent publications include "Gesture and Calligraphy in the Late Works by Chou Wen-chung" in Contemporary Music Review 26.5-6 (2007) and The Music of Louis Andriessen (Cambridge University Press, 2006).

c. Catherine losada is Assistant Professor at the CollegeConservatory of Music, University of Cincinnati.

wayne Marshall is the Florence Levy Kay Fellow in Ethnomusicology at Brandeis University

timothy R. mckinney is Associate Professor of Music Theory at Baylor University.
DAvid pacun is Associate Professor of Music Theory at Ithaca College. His research interests include Brahms, Music Theory Pedagogy, Disabilities Studies, and Interwar Japanese Music.

OLLI VÄIsÄLÄ is Senior Assistant of Music Theory at the Sibelius Academy, Helsinki. 